Tesis. Año 14, 13(17), 2020, 21-36

\title{
Encuentros de dos mundos: contactos lingüísticos entre andinos y amazónicos en el siglo XIX
}

\author{
Óscar Huamán Águila \\ oscar.huaman3@unmsm.edu.pe
}

\section{Resumen}

El presente trabajo abordará el contacto lingüístico de la lengua quechua con algunas lenguas Arawak de la vertiente oriental de Ayacucho durante el periodo del siglo XIX. En los diarios de los viajeros, que incursionaron hacia el piedemonte, se muestra que existieron pobladores amazónicos que hablaron la lengua quechua, y de igual modo, se evidenció que los quechuahablantes tuvieron dominio de alguna de las lenguas amazónicas. Este fenómeno lingüístico y cultural se muestra en los textos de Antonio Raimondi (1866), de José B. Samanez Ocampo (1884) y de Pedro Portillo (1890). Este hecho se debe al contacto lingüístico de ambas culturas que se dio en las fronteras desde muchos años antes a la intromisión española y a la incursión de los viajeros. El tema de investigación será abordado desde un enfoque sociolingüístico y desde una metodología de revisión y análisis de fuentes escritas.

Palabras claves: Diarios, contacto lingüístico, quechua-arawak, frontera cultural, viajeros del siglo XIX.

\section{Abstract}

This paper will address the linguistic contact of the Quechua language with some Arawak languages of the eastern slope of Ayacucho during the period of the 19th century. In the diaries of travelers who made their way to the foothills, it is shown that there are Amazonian inhabitants who speak the Quechua language, and from the same way, it was shown that the Quechua speakers have mastered some of the Amazonian languages. This linguistic and cultural phenomenon is shown in the texts of Antonio Raimondi (1866), José B. Samanez Ocampo (1884), Pedro Portillo (1890). This fact is due to the linguistic contact of both cultures that took place at the borders for many years before the Spanish and traveler's interference. The research topic will be approached from a Sociolinguistic approach. And from a methodology of revision of written sources and analysis.

Keywords: Diaries, linguistic contact, Quechua-Arawak, cultural border, 19th century travelers. 


\section{Encuentros de dos mundos: contactos lingiirísticos entre andinos y amazónicos en el siglo XIX}

\section{Introducción}

En este trabajo nos aproximaremos a la presencia y al contacto lingüístico entre la lengua quechua y algunas lenguas de la familia Arawak, en la parte oriental de Ayacucho durante el siglo XIX. Esto a partir de los diarios del viajero y de los exploradores que registraron durante su entrada hacia las montañas de Huanta. Si bien no fue el objetivo principal de los autores de los textos, de dar cuenta de la realidad lingüística del piedemonte, sin embargo lograron registrar aquella realidad. Con esto último nos referimos al bilingüismo que subyace tanto en los quechuahablantes y en los miembros de los pueblos amazónicos. Asimismo, se registra la presencia de las culturas preandinas en las estribaciones orientales de la cordillera andina de Ayacucho.

Los textos mencionados en esta sección, nos ayudan a esclarecer nuestra investigación sobre el periodo de contacto entre las lenguas estudiadas en el presente trabajo, así también, la presencia de las culturas amazónicas en los contrafuertes de las cordilleras andinas y el uso de más de una lengua amerindia por parte de los pobladores indígenas. En ese sentido, hemos seleccionado los diarios pertenecientes a Antonio Raimondi, José B. Samanez Ocampo y Pedro Portillo, puesto que hay elementos que nos permiten aproximarnos a esas tres realidades. Ellos lograron entrar al piedemonte por sus intereses personales y académicos como es el caso del viajero Raimondi; en el caso de los restantes, se podría decir que fue motivado por un interés "nacional" (colonización). Los tres estuvieron en las montañas de la provincia de Huanta, Lamar y río Apurímac. La presencia del italiano data del año 1866, de Samanez entre los años 18831884 y de Portillo en los años 1896-1900. En esta travesía lograron describir la realidad lingüística de la vertiente oriental de Ayacucho.

Sobre este tema de contacto lingüístico entre los quechuahablantes y algunos pobladores de comunidades amazónicas que hablan alguna lengua Arawak, en la parte de Ayacucho, no ha sido estudiada hasta la actualidad. Al respecto, 
el presente trabajo logra cubrir ese vacío y abrir una discusión académica, en vista de que existe una necesidad nacional de comprender y de buscar una interculturalidad. Las investigaciones con respecto al tema de contacto de ambos pueblos son incipientes. Con esta afirmación no queremos decir que no hay algunos trabajos, de ninguna manera. Existen investigaciones del contacto de las lenguas andinas y amazónicas. Incluso desde las fuentes similares a lo nuestro, como más adelante veremos en la sección de antecedente.

La existencia de los bilingües indígenas en aquel tiempo y espacio, se debe a un contacto lingüístico que se dieron muchos años anteriores a la intromisión del mundo occidental en la zona. Por esta razón había algunos bilingües en las comunidades amerindias. Esto sustenta en los diarios del siglo XIX. En relación a esto nos hemos trazado el objetivo de determinar el carácter bilingüe de la población amerindia y la presencia de los amazónicos en los contrafuertes de las cordilleras andinas.

Esta realidad lingüística, es decir, el manejo de alguna lengua amazónica por parte de quechuahablantes y el uso del quechua por pobladores de algunas comunidades amazónicas, están presentes en los tres diarios mencionados. Pero lo que no está claro es cuál de las lenguas Arawak eran hablados por los pobladores quechuas; en cambio, en el caso de los pueblos amazónicos que sí tenían conocimiento del quechua. Si bien, en los diarios estudiados, tanto del viajero italiano como de los exploradores peruanos, se mencionan que los pobladores de las montañas de Huanta y Lamar eran denominados como campas, chunchos, salvajes, infieles, catongos, estas denominaciones lingüísticas nos ayudan mucho a colegir algunos conceptos, ya que a todos los que vivían en la selva se les conocía con esos términos antes y durante esos periodos. Por ese vacío de información de idioma que existe, hemos preferido señalar que los pueblos que estuvieron en las estribaciones de la cordillera andina, en esos periodos, fueron poblaciones que hablaban lenguas pertenecientes a la familia Arawak y por los términos recogidos en los manuscritos.

Lo más probable es que, en ese siglo y en los anteriores, estuvieron presente los pueblos que pertenecían a la cultura Arawak. Porque, lo que se encuentra en los diarios de los franciscanos que ingresaron hacia la amazonia durante en el siglo XVII, a las montañas de Ayacucho, se vuelve a repetir las mismas denominaciones en los textos del siglo diecinueve. Esto nos lleva a plantear que posiblemente estuvieron los pueblos asháninka, matsigenka, nomatsigenka, kakinte, etc. Son mínimos los elementos lingüísticos que aparecen en los diarios para poder determinar con exactitud las comunidades que se menciona. Uno de los ejemplos que podemos ver en el texto de Portillo es la expresión pituches (canoas). Está palabra está registrada en el vocabulario machiguenga de Pío Aza (1923) como pitu-chi 'mi canoa'. Como se podrá percibir en ambos autores, el término alude a la misma realidad. Esto nos conduce a señalar que lo más 
probable es que estuvo la cultura matsigenka en ese espacio y en aquel tiempo. Las evidencias no son suficientes para poder establecer la filiación lingüística y a esto se suma el carácter semisedentario de los pueblos amazónicos.

\section{Antecedentes}

Con respecto a los estudios precedentes sobre el contacto del quechua Ayacucho-Chanca y las lenguas Arawak no contamos con investigaciones que aborden dicho fenómeno lingüístico hasta la fecha. Pero sí hay en relación del contacto lingüístico entre las lenguas andinas y amazónicas; es decir, trabajos realizados de manera específica, como el caso del contacto de las lenguas ashéninka y el quechua, así como del asháninka y quechua, y sobre la confluencia de alguna lengua amazónica con la andina en la zona nororiental del Perú.

Uno de los estudios que aborda de manera general el contacto lingüístico del quechua con las lenguas amazónicas es el de Solís Fonseca (2001). El señala que hubo confluencias entre ambas lenguas durante el incanato. Es decir que:

la selva adyacente comienza a ser intervenida por los incas, generándose en ese contexto un intenso contacto de los pueblos andinos y amazónicos, varios de estos últimos terminaron quechuizados, cambiando muy radicalmente su cultura, y desplazándose de lengua para devenir en hablantes de runasimi (Solís Fonseca, 2001, p. 11).

Por este factor social que se produjo en esos años, los pueblos que estuvieron en la parte oriental de las cordilleras andinas llegarían a ser hablantes de la lengua general. En otras palabras, a partir del ingreso del quechua se inicia un proceso de quechuización de los amazónicos. Además, se menciona que el proceso de entrada de la lengua andina hacia la amazonia tuvo varias etapas. Para Solís Fonseca (2001) el primero, como acabamos de mencionar, sería durante la época prehispánica; la segunda, durante la Colonia (con la evangelización) y la tercera, durante la República (época del caucho).

En esta línea de investigación se encuentra el trabajo de Alonzo. Ella señala que los avances en las investigaciones históricas, arqueológicas y lingüísticas han logrado revelar que los antiguos grupos amerindios tuvieron un contacto. Este fenómeno se habría producido entre ambas culturas por "las condiciones geográficas, sociales, políticas, religiosas y económicas” (Alonzo, 2002, p. 74). Para ella se daría durante al periodo prehispánico y posterior a ello. Este último correspondería a la época de la evangelización por parte de los jesuitas; es decir, durante la Colonia. Ahora, con respecto al influjo de expresiones, los términos se darían de manera recíproca; es decir, del quechua hacia las lenguas amazónicas y de las lenguas amazónicas hacia la lengua quechua. Este último no está de manera explica en el artículo, pero se logra deducir de los ejemplos que analiza. Por este fenómeno lingüístico habría llegado la palabra Antis a la lengua 
quechua, en este caso de la familia lingüística Arawak. También las expresiones pongo, mitayo habrían seguido el mismo camino.

Las otras investigaciones tienen que ver con el préstamo del quechua hacia las lenguas ashéninka y asháninka, pertenecientes a la familia Arawak y con otra lengua amazónica del Nororiente. Estos trabajos son de carácter intralingüístico. Entre ellos se encuentra los estudios de Jacinto, Yanqui y Freixa (2011), de Alonzo y Ramos (2014), de Vílchez (2015), y Faucet (2017). En dichos trabajos encontramos que hubo un contacto lingüístico y un préstamo de términos a las lenguas amazónicas desde la lengua quechua. También encontramos que, con respecto a la familia lingüística Kawapana, Valenzuela (2015), se menciona que hubo un influjo de aspectos lingüísticos de las lenguas andinas (quechua y aimara).

\section{Marco teórico}

En la presente sección abordaremos los conceptos del bilingüismo y contacto de lenguas; dado que en los diarios de los exploradores y viajeros se presentan a las personas que hablan una lengua amerindia (distinta a la lengua materna). La explicación a este fenómeno se dará desde una teoría sociolingüística.

Desde un enfoque sociolingüístico hay varios procesos que se producen cuando hay dos lenguas que comparten el mismo espacio. Debido a que los sujetos interactúan en esa comunidad lingüística. En esta realidad es donde las personas son susceptibles a adquirir una lengua ajena para comunicarse. A esta realidad García (2015) lo denomina bilingüismo; es decir: "Por bilingüismo se entiende la capacidad que posee un individuo para comunicarse mediante más de una lengua" (p. 168). No obstante, para poder denominar bilingüe a la persona no solo tiene que manejar algunas palabras, sino un cierto dominio. Además, menciona que no toda la población tiene que utilizar el otro idioma para poder catalogarse como bilingüe.

Para que se produzca este fenómeno lingüístico en una comunidad monolingüe, necesariamente tiene que haberse dado un contacto de lenguas por una realidad social. Porque sin ello no se puede generar dicha realidad; en otras palabras: "Las lenguas no se influyen unas a otras en el vacío, sino que hay diversas clases de dinámicas sociales que así lo propician” (García, 2015, p. 176). Por este factor se daría la necesidad de aprender un idioma más por un sujeto monolingüe. Para no distanciarnos del concepto del contacto de lenguas, mencionemos lo que señalan Alonzo y Ramos. Para ellas "El contacto de lenguas surge cuando dos lenguas se hablan en la misma sociedad; tal situación conlleva a que surja, como consecuencia inmediata, los préstamos lingüísticos" (Alonzo y Ramos, 2014, p. 84). De esta realidad no fueron ajenas las culturas andinas 
y amazónicas que se encontraban durante el siglo XIX en la parte oriental de Ayacucho.

\section{Metodología}

Para la presente investigación hemos seleccionado los diarios de los exploradores y del viajero del siglo XIX y de los inicios de siglo XX. Porque en los manuscritos se muestra la presencia de los pueblos amazónicos en las estribaciones orientales de las cordilleras andinas de Ayacucho, así como, el bilingüismo de los indígenas andino y amazónico. Esto último tiene que ver con el dominio del quechuahablante de alguna lengua Arawak y de pobladores amazónicos con respecto a la lengua quechua.

En ese sentido nuestra metodología consiste en la revisión de fuentes escritas y en el análisis de los textos escritos del siglo XIX. Desde luego hacer aproximaciones al contacto lingüístico de las poblaciones quechuas con los pueblos de la lengua Arawak, y de estos últimos con el anterior. El proceso que se tomó en este trabajo fue la búsqueda de fuentes bibliográficas del periodo mencionado, después se siguió la selección de los diarios y por último el fichaje de los elementos con respecto al tema propuesto.

\section{Resultados y discusión}

El interés de ingresar hacia la Amazonía por parte del mundo occidental no es solo de este contexto que nos toca ver, sino comienza en los periodos de la $\mathrm{Co}^{-}$ lonia española. En este proceso de entrada a la amazonia han logrado describir la realidad lingüística y cultural de las montañas de Ayacucho. En ese sentido, aquella circunstancia ha quedado plasmada en los diarios de las personas que llegaron a esos espacios mencionados.

En los textos recogidos para la presente investigación existen evidencias sobre el periodo de relación que han mantenido ambos pueblos indígenas. Cabe mencionar que durante nuestra búsqueda solo logramos encontrar tres diarios, suponemos que es posible que existan otros más. El primero en ingresar, de acuerdo a nuestro interés, hacia las montañas de Ayacucho fue Raimondi. Lo resaltante de él no radica en el carácter predecesor a los demás, sino su determinación de la frontera cultural que existía entre los quechuas y los amazónicos en los contrafuertes de la cordillera andina. Ya que los demás ya no mencionan este aspecto. El viajero italiano señala: "Monterico es la última hacienda de las montañas de Huanta, hallándose en el límite de los terrenos habitados por los salvajes, que en muchas partes del Perú llaman Infieles o Chunchos" (Raimondi, 1874, p. 247). El espacio que menciona está en la parte oriental de la cordi1lera de Ayacucho. Este espacio era el límite cultural, en aquellos tiempos, entre andinos y la cultura Arawak (llamado chunchos). Incluso el hombre occidentali- 
zado llegaba hasta ese espacio físico. Porque a partir de aquel lugar los "terrenos [están] poblados por salvajes" (Raimondi, 1874, p. 447). En otros términos, los territorios que descienden hacia la ceja de selva de Huanta ya no están poblados por indios (población quechua) y los occidentalizados (hacendados); sino es el espacio de los pueblos de piedemonte. Cabe precisar, con respecto al lugar aludido que esta frontera cultural se encuentra muy próximo a los ríos Apurímac y Mantaro. Esta presencia de la cultura amazónica se va a intensificar a medida que se acerca a ambos ríos.

Después de haber cruzado esta frontera territorial y cultural, se logra ingresar al espacio habitado por algunas comunidades que hablan algunas lenguas de la familia lingüística Arawak. Raimondi señala:

[U]n cuarto de legua más allá al salir de la espesura del bosque nos hallamos delante de una casa o más bien sotechado donde vivían algunos salvajes, de los cuales tuvimos buena acogida, habiendo sido obsequiados con grandes piñas, y mis cargueros con su favorecida bebida, preparada con yuca fermentada, que aquí llaman istía. (Raimondi, 1874, p. 248)

Raimondi no solo logra registrar a la población amazónica en las montañas, sino también describe algunos aspectos culturales como el tipo de bebida que solían beber. Inclusive el nombre con la que conocen aquel producto. Lo que habrá que subrayar de este pasaje es la distinción cultural que hace cuando menciona a las personas del lugar con el término salvajes. Esto quiere decir que no son indios (quechuas) ni mestizos o criollos los habitan en la montaña de Huanta. Cabe mencionar con respecto a esa expresión que, durante el siglo XIX e inclusive en los siglos anteriores, esto se utilizaba para demarcar la identidad cultural y espacial. Los indios habitaban en los andes y los salvajes en las montañas.

La presencia de la población amazónica en este espacio, va a ser constante durante su trayecto hacia el río Mantaro. Más adelante logra percibirlos en las riberas del río Apurímac. Veamos en la siguiente cita: "Nos hallábamos casi en la mitad del camino, cuando encontramos una canoa con cuatro salvajes que venían bajando velozmente en medio del río. A una señal que les hicieron los que me acompañaban vinieron luego" (Raimondi, 1874, p. 252). Pero en cada encuentro hay algo nuevo que menciona. En este caso ya son navegantes. Más adelante vuelve a encontrarse con una comunidad que ya no son solo personas dispersas (sin organización jerárquica); sino hay una familia que cuenta con un jefe. Él señala que "El jefe de esta familia, llamado Subiri [...] hace sus viajes río abajo hasta el río Tambo" (Raimondi, 1874, p. 251). A parte de lo dicho, en la cita se muestra que los indígenas de las montañas de Huanta son viajeros en el río Tambo. Este último lugar se encuentra en el territorio del departamento de Junín. Esta actividad fluvial del preandino no solo aparece en este texto, sino también en el diario de Samanez y de Portillo. Esto es con respecto a la presen- 
cia de los pueblos amazónicos en la vertiente oriental de Huanta, del siglo XIX por parte del viajero italiano.

La presencia de los pueblos amazónicos en las estribaciones de la cordillera andina del oriente de Ayacucho está también en los diarios de Samanez y Portillo. Ellos durante su exploración han registrado en sus escritos la realidad del espacio geográfico y la existencia de los pueblos indígenas en las orillas de los ríos Apurímac, Mantaro, Ene, Tambo y Ucayali. Pero al mismo tiempo registraron la presencia de algunos pueblos amazónicos bilingües en lengua amerindia. Sobre esto último volveremos más adelante.

Portillo, siguiendo la ruta que hizo del viajero italiano, ingresó a los ríos mencionados que se ubicaban en la parte oriental de Huanta; en cambio Samanez lo hizo por Chungue-Lamar. Este último lo realiza por esa zona porque parte de Andahuaylas. En otras palabras, por esa parte de Ayacucho es muy cerca al punto de entrada hacia la amazonia. Portillo en su ingreso al río Apurímac avista a la población indígena de piedemonte. Lo cual se muestra en el siguiente enunciado: "Cuando llegamos á la playa de Apurímac [...] Vemos encalladas á la orilla, dos embarcaciones, los pituches, especies de grandes guigs de regatas, de un solo madero, sin pintura ni piezas. Los salvajes los manejan rio arriba por la orilla, con carrizo; río abajo, con remo de brazo corto y paleta ancha (sic) (Portillo, 1901, p. 15). Esta misma escena se repite en el encuentro de los ríos Mantaro y Apurímac. Veamos en el siguiente pasaje: "Los salvajes que habitan los ríos Mantaro y Apurímac, son los campas, en número aproximado de quinientos" (Portillo, 1901, p. 19). En ambos espacios se menciona la presencia del pueblo amazónico, pero en el último texto aparece una población grande. El lugar que indica se encuentra en la frontera de Ayacucho y Junín. Además, es la frontera territorial entre las variedades del quechua, porque hasta esta área llega el quechua wanka y Ayacucho-Chanca. También está próximo a la comunidad quechua de Sanabamba, donde se centra nuestra presente investigación. Retomando el tema, el explorador da cuenta que, en los encuentros del río Mantaro y Apurímac existió la presencia numerosa de pueblos, probablemente pertenecientes a la familia lingüística Arawak. Esto nos permite señalar que el espacio mencionado, durante ese año y posiblemente anterior a ese periodo, estuvo habitado por una comunidad amerindia.

El otro elemento que subyace en este enunciado es la denominación de campa que recibe la población amazónica. Si bien en las anteriores menciones utiliza el término salvajes, en este caso cambia y los llama con los nombres: infiel, salvaje, chuncho. Tal vez las diferentes denominaciones se deban a la diferencia étnica de los pueblos amazónicos por parte del explorador. Sin embargo, esto no es suficiente para definir a qué grupo étnico se refiere. Para Santos y Barclay (2005), durante el siglo XVII, con el término campa se referían a nomatsiguenga, asháninka, kakinte, matsigenka y yánesha. Lo que no hay duda es que estamos 
ante la presencia de pueblos que pertenecieron a hablantes de lenguas de la familia Arawak de la parte oriental de Ayacucho.

Para finalizar esta parte, con respecto a la presencia de la cultura amazónica en los territorios adyacentes a los pueblos quechuas en las estribaciones orientales de las cordilleras de Guamanga, veremos el diario del explorador Samanez. Este diario es otra fuente que nos permite aproximarnos a la realidad social de las montañas de Ayacucho. El en su viaje de 1879 alcanza presenciar a la población indígena de piedemonte en Anchihuay. Esto se muestra en la siguiente cita "llegué hasta el rio 'Anchihuay', que sirve de límite, por esa parte, entre las provincias de Lamar y Huanta. [...] Es yá navegable en canóas y balsas, como lo hacen los salvajes 'campas' que habitan allî" (sic) (Samanez, 1980, p. 19). Para el explorador el espacio está ocupado por grupos humanos llamados "salvajes". El lugar mencionado, en el mapa de la colonia se encuentra en la parte izquierda de río Apurímac. Esta presencia se va a repetir de manera constante en sus exploraciones posteriores al oriente. En algunas circunstancias logra describir con más detalles y en otros no; tal es el caso del año1884, en la que menciona:

Los salvajes que habitan en las márgenes de este gran rio, desde donde solo es Apurimac hasta donde se convierte en Tambo, pertenecen á la tríbu de los campas, y están divididos en dos grandes secciones: los catongos ó catongosates, que principian desde el rio Pampaconas y terminan antes del Quimbiri-grande y los camáticas, llamados mas comunmente entre ellos queringasates, de la voz queringa que quiere decir abajo, asi como la de catongo significa arriba. Cada una de estas secciones tiene un dialecto distinto, derivado de la misma lengua madre. Los catongos hablan casi con voz natural, mientras los queringas parece que cantaran al hablar (sic). (Samanez, 1980, p. 60)

En el fragmento se menciona de manera explícita la existencia de varios grupos étnicos que pertenecen al pueblo campa. Asimismo el territorio que ocupan ellos, en referencia al río. Ellos, según el explorador, están afincados en los bordes del río Apurímac que pasa por las tierras de Lamar y Huanta, del departamento de Ayacucho. Esta distinción que hace llama la atención, porque hay una diferencia espacial (arriba y abajo) y también el aspecto lingüístico (forma del habla) de la población campa. Como se puede notar en el texto, la existencia de grupos conformados por catongos-catongosates y camáticas- queringasates, la ceja de la selva está poblada. No obstante, menciona que ambos son del conjunto campa y están segmentados en catongo (arriba) y queringa (abajo), en referencia a la ocupación espacial del río. Por otro lado está el factor que la diferencia del uno con el otro; tal es el caso de la característica suprasegmental del habla de ambos grupos. Por ejemplo, en el primer grupo el habla se da de manera natural, mientras que en el segundo en forma de canto. Desde 
luego estamos ante la presencia de distintas lenguas Arawak. Si no existiera esa realidad lingüística no mencionaría esa parte de su medio de comunicación.

Hasta esta parte podemos mencionar que sí hay una presencia masificada de las poblaciones amazónicas en la parte oriental de Ayacucho, desde mediados del siglo XIX hasta el primer año del siglo XX. A hora veremos en los siguientes párrafos el bilingüismo de los indígenas y el manejo de las lenguas amerindias, tanto del poblador quechua como del amazónico. Esta realidad lingüística en los indígenas está presente en los tres diarios como veremos a continuación.

El carácter bilingüe de los pueblos andinos y amazónicos se muestra cuando se menciona al intermediario entre el sujeto occidental y la población del piedemonte. En esas circunstancias se visibiliza la existencia del sujeto indígena bilingüe; en otras palabras, en la imagen del intérprete. Ya que el viajero y los exploradores no manejan la lengua de las comunidades que están en las márgenes de los ríos por donde viajaban. En algunos textos se muestra de manera breve o extensamente sobre el personaje intermediario. La existencia de una persona amerindia (andino o amazónico) que habla más de una lengua cuando se encuentran con las comunidades indígenas. También en los nombres de los lugares, en lengua ajena al castellano, que aparece en los diarios. Sin ellos, sería imposible de saber cómo se denominan tal lugar, porque para esa época no hay letreros en las comunidades como si estuviéramos en la urbe moderna. Aquí ellos son invisibles, pero los términos nos anuncian que hay alguien detrás de eso. Desde luego hay otros aspectos más que se pueden estudiar en los diarios, pero ahora solo nos quedamos con ese aspecto lingüístico.

Como mencionamos en líneas anteriores, hay bilingüismo en algunas personas quechuas y amazónicas. Ellos utilizan como medio de comunicación alguna lengua Arawak. La población que habita en la montaña también lo hace con el dominio de la lengua quechua. Siguiendo la cronología de entrada, en los años 1866, el viajero italiano menciona sobre ese aspecto lingüístico de la población quechuahablante. Durante su ingreso hacia la selva de Huanta consigue una persona bilingüe y conocedor de las montañas de la parte oriental de Ayacucho. Raimondi señala que:

En Monterico tuve la felicidad de hallar a un viejo indio bastante práctico de aquellos bosques, y que entendía además algunas apalabras del idioma de los salvajes campas, los cuales se conocen aquí con el nombre de Catongos, nombre también que se aplica en esta parte del Perú al río Apurímac en cuyas orillas habitan. Contraté pues á este Indio para que me sirviese de guia é intérprete, y á otros cuatro para cargar los víveres y lo necesario para una expedición de algunos días (sic). (Raimondi, 1874, p. 447) 
En la cita se menciona que Raimondi consigue una persona para que le sirva de guía e intérprete, que comprendía y hablaba la lengua amazónica. Lo que nos interesa remarcar aquí es que el «viejo indio» como lo denomina Raimondi, hace referencia a un quechuahablante que conocía la lengua campa; es decir, alguna lengua de la familia Arawak. Ambos elementos nos permite colegir que estamos ante dos pueblos que estuvieron relacionados, pues hay un conocimiento de una lengua, aparte de su lengua materna. Sin ello sería imposible que existiera un sujeto bilingüe.

Partiendo de los anterior queremos remarcar entonces, que la filiación cultural del intermediario, del intérprete no es mestizo ni criollo, sino es un indio. Con este último término, en esa época, se les conocía a las personas que hablaban la lengua quechua. En cambio, a los amazónicos con las expresiones campa, chunchos, salvajes, infieles, etc. Esas denominaciones serán, para el mundo occidental o el occidentalizado, líneas divisorias fundamentales para determinar el sujeto en una cultura determina. A esto se suma la ocupación espacial, los indios habitan en la sierra y los salvajes en la montaña. Esta determinación étnica está clara en lo que menciona Raimondi. Por esta diferenciación hecha es que sabemos que estamos ante una persona bilingüe quechua, y por el manejo de la lengua amazónica. Como se mencionó en líneas anteriores, por esta competencia comunicativa que tiene el sujeto andino es tomado como intérprete. A esto se añade el conocimiento geográfico de la zona de la ceja de la selva.

El conocimiento de una lengua amerindia por parte de los indígenas, no solo es de los que se encuentran en los andes sino también es parte de los amazónicos. Lo mencionado se evidencia en las personas que hablan la lengua quechua, por supuesto, aparte de su lengua materna. Ahora con respecto a su ubicación territorial, ellos están en las montañas de la vertiente oriental de Ayacucho. Por ejemplo, en el diario de Samanez de 1883 se menciona lo siguiente: "Les pregunté si existía Inocencio (infiel que me sirvió de intérprete el año 79, por que sabe la quíchua) y me dijeron que sí” (sic) (1980, p. 31). En el fragmento se menciona de manera explícita que Inocencio no es indígena quechua, sino infiel. Sin embargo, conoce la lengua quechua, a parte de su idioma materno. En esta parte del enunciado vale detenerse, debido a que hay un aspecto que requiere dilucidar. La pregunta que surge es la siguiente ¿a Inocencio lo toma como intérprete por el conocimiento del quechua o por su dominio de la lengua amazónica? En primera instancia, se puede afirmar que es por el manejo de la lengua andina, puesto que Samanez es andahuaylino y lo más probable es que hablara quechua de variedad ayacuchana. Por esta razón necesita una persona que hable dicha lengua y a la vez la lengua de anti. Su función sería traducir lo que dice el explorador a la población amazónica y de lo que expresan sus congéneres. Además, Inocencio no solo era intermediario entre la población y él, sino también para dictarle los nombres de los ríos, lugares y comunidades que se encuentran en el trayecto hacia Ucayali, ya que cada lugar no cuenta con una 
señalética. Lo que sí es muy forzado es plantear que la población que se encuentra en la orillas de los ríos mencionados más arriba hablan la lengua quechua. Como se puede ver, solo son algunas personas que dominan la lengua andina. Lo que sí está claro es que Inocencio maneja la lengua de los pobladores que se encuentra en esa parte del territorio (orillas de los ríos Apurímac, Mantaro, Ene, Tambo, Ucayali), y su contrato no es tanto por su dominio de la lengua andina.

La presciencia de las personas bilingües en la parte oriental de Huanta y en Ayacucho, durante el siglo XIX, aparece de manera constante en los tres diarios. Inclusive en los diarios de los franciscanos que entraron en el siglo anterior; a esto subyace aquella realidad lingüística. En ambos pueblos se encuentra el sujeto indígena bilingüe en una lengua amerindia. Este es el caso que menciona Samanez, en el viaje posterior, durante su ingreso hacia la Amazonía peruana:

[A] poca distancia de aquí, residían muchos campas, y entre ellos, estaba radicado un huantino llamado Mariano Soto, el cual, el año 1879, estuvo en Sinquebeni y sirvió de intérprete [...] cuando vine hasta Anchihuay. Le hice llamar esta mañana; pues lo necesitaba para intérprete: habla regularmente el campa, ademas de la quichua, que es su idioma (sic). (Samanez, 1980, p. 37)

El lugar que menciona es parte del territorio oriental de Ayacucho, es decir se encuentra antes de la confluencia de los ríos Mantaro y Apurímac. A partir de este espacio comienza el río Ene. De esta parte de la cita nos interesa señalar lo siguiente: durante esos periodos había una convivencia de las personas quechuas con los amazónicos. Esto sería uno de los factores que haya permitido crear esa realidad lingüística en las poblaciones. También refuerza la hipótesis del contacto de ambos pueblos de manera constante, aunque débil, en las montañas de Guamanga.

Esta imagen de manejo de dos lenguas amerindias por parte de las personas indígenas se va a evidenciar también en el río Tambo. El explorador durante su navegación en el río Tambo se encuentra con un grupo de amazónicos y lo menciona de la siguiente manera: "Luego que se reunieron con nosotros, entraron en nuestras balsas con el mayor desembarazo y confianza, hablándonos en piro, en campa, en mal quéchua y hasta en castellano" (Samanez, 1980, p. 37). En esta parte de la selva ya se menciona la presencia de los piro (yine), etnia perteneciente a la familia lingüística Arawak, pero no parte de la etnia campa que se encuentra en las orillas de Apurímac, Mantaro y Ene. Cabe advertir sobre el conocimiento del quechua, que no se sabe cuál de ellos la habla. Tal vez una sola persona habla dichos idiomas o todos se comunicaban en esa lengua. Lo que está claro es con respecto a la presencia de varios grupos amazónicos. Lo que sí nos llama la atención es la presencia del quechua en esta parte de la montaña. El lugar mencionado ya no está cerca de las montañas de Guamanga. 
El otro explorador de la zona amazónica que ingresa por el espacio de Ayacucho, también logra registrar esta realidad lingüística de las personas que pertenecen al pueblo indígena del Perú. Portillo entra en el siglo XIX y en los inicios del siglo XX. En esta incursión que realiza hacia la selva, otra vez se evidencia la presencia del bilingüe en una lengua amerindia, en la figura del intérprete. Aquí son varias personas con esas habilidades lingüísticas.

Portillo, el 18 de mayo de 1900, parte desde la ciudad de Ayacucho con una comitiva conformada por los militares hacia las montañas de Huanta y del río Ucayali. En esta expedición van varios bilingües. Veamos en el siguiente enunciado: "Intérpretes montañeses - José Delgadillo, de Choymacota, y Mariano Prado de id.; Matías Mendoza, de Acón, Andrés Palomino de id., Andrés de id., Nicolás Tello de id., Melchor Huachaca, de Puerto Huaura" (Portillo, 1901, p. 9). Ellos van en calidad de traductores. Pero no se sabe que lengua hablan o a qué grupo indígena pertenecen, ya que no se menciona en el texto. Sin embargo, podemos aproximarnos a su pertenencia cultural y la lengua que dominan, tomando en cuenta el lugar de procedencia de cada uno de los que se mencionan y por el origen de los apellidos. Los lugares que se mencionan son, lo más probable, área quechua, excepto el puerto Huaura. Porque este último se encuentra en el río Apurímac, según la mención de Portillo. En cambio, las demás zonas son de las cordilleras orientales, o sea, de las estribaciones andinas que se conectan con la ceja de la selva de Ayacucho. El caso de Huachaca nos lleva a plantear que es un sujeto quechua. El otro elemento que nos facilita delimitar o vincular es la diferenciación social que hace Portillo. Él menciona que parte de la empresa de exploración son los "Salvajes que manejaban las balsas y canoas de la expedición-Quince [son] de puerto Huaura y Quimpitirique, cuyos jefes eran Mackinley y Eugenio; dos de Chiquirini" (Portillo, 1901, p. 10). Tanto el lugar de procedencia de estos dos grupos (intérpretes y conductores) y la función que cumplen en la empresa de navegación, nos permite comprender que estamos ante dos clases de indígenas. Si fueran los traductores de la misma etnia de los amazónicos que conducen la embarcación, no habría una necesidad de mencionar o llamarlos con intérpretes, sino a ambos los nombrarían con el término salvajes. Ahora, con respecto al dominio de la lengua, sí se deduce del enunciado, puesto que están para intermediar con los pueblos que no hablan castellano. Además, eran conocedores de alguna lengua de las comunidades que se encuentra en los ríos mencionados.

A partir de este aspecto social que se establece para diferenciarlos del uno y del otro, en otras palabras, la designación para un grupo de personas intérprete y para otro salvaje podemos afirmar que esos últimos son amazónicos. A esto se puede agregar lo que se menciona en los demás diarios. En todos está presente dicha expresión y dirigido de manera genérica a los pueblos amazónicos. Pero en contraposición al "civilizado", esta dicotomía de manera explícita se muestra cuando señala Portillo (1901) que "En sus márgenes no habita una persona 
civilizada. Sus moradores son salvajes campas" (p. 26). Los civilizados serían los mestizos o los criollos que tienen la hacienda, y por último los caucheros que ya están en esa época por esa parte del territorio amazónico. El lugar que menciona es el río Ene.

Los llamados intérpretes no tienen solo la función de hacer el papel de intermediarios entre el explorador y la población amazónica, sino también tienen conocimiento de los espacios geográficos y las comunidades que se encuentran en los márgenes de los ríos Apurímac, Mantaro, Ene y Tambo. En ese sentido, ellos están detrás de cada nombre que aparecen en los diarios. Veamos como ilustración en el siguiente pasaje: "Tampoco pudimos averiguar el nombre de estos cinco ríos, porque el intérprete no sabía" (Portillo, 1901, p. 32). El conocimiento de las montañas y el manejo de una lengua amerindia de los indígenas nos inducen a señalar que ambos pueblos de la zona de Ayacucho, en esos periodos y anteriores, eran dinámicos. En otras palabras, hubo una interrelación cultural y lingüística entre los dos pueblos. Sin este factor no existiría esa realidad lingüística que se menciona en los textos. Y también nos sugiere que esa parte de la amazonia era un espacio de interconexión, debido a que los ríos mencionados servirían como medio de comunicación, por su carácter de ser navegables. Una de las evidencias de esa realidad serían los intérpretes que se mencionan en los textos y la presencia de la lengua quechua en el río Tambo. Inclusive se menciona que "Juan Santos penetró en la montaña por el lado de Huanta y avanza hasta el Gran Pajonal, guiado por el curaca simirinche [...] Bisabequi" (Valcárcel, 1974, p. 74). Esto es en el año 1742. Lo más posible es que sea cierta la mención, puesto que está más próximo a un río navegable hacia Gran Pajonal. Desde luego, como se menciona de los exploradores, hay una navegación constante por esta parte del río.

Hasta esta parte exponemos nuestra descripción y comentario sobre la presencia de la población amazónica y el bilingüismo existente en pobladores pertenecientes a la cultura quechua y amazónica. Cabe mencionar que los diarios del siglo XIX nos permiten aproximarnos a una realidad lingüística y social que se había generado en esa parte del territorio del departamento de Ayacucho. Además, nos ha permitido retornar en el tiempo y así podemos determinar el contacto de ambos pueblos amerindios. Esto despeja un poco esa frontera infranqueable que existe en nuestro imaginario cultural del Perú. Tanto el viajero italiano y los exploradores solo dan cuenta del espacio que han recorrido. No sabemos a ciencia cierta de los demás lugares que se extiende desde Apurímac hasta las fronteras de Huancavelica y Junín. Lo que nos muestra los textos es una línea o mejor dicho un solo espacio en cuanto la superficie territorial, pues hay múltiples territorios que se encuentra en la parte oriental de la cordillera que pasan por la provincia de Huanta. Lo más probable es que se repita esa misma realidad en otras comunidades que se encuentra en los contrafuertes de las montañas y en las cercanías de los demás ríos afluentes a Apurímac y a 
Mantaro. También en las comunidades quechuas que se encuentra en la parte occidental.

Al mismo tiempo, nos ha permitido ver la coexistencia de varias capas sociales de aquel entonces en la frontera cultural. Dado que no solo están presente las comunidades en la amazonia y los quechuas, sino también están los hacendados (occidentales). Desde luego la presencia de la lengua castellana como un medio de expresión de este último grupo social. De esta realidad lingüística vale resaltar, aunque ya hemos mencionado en líneas anteriores, el conocimiento de los quechuahablantes de una lengua amazónica y el de los pueblos del piedemonte el conocimiento del quechua. Ambos son bilingües de alguna manera. Esto nos lleva a plantear lo siguiente: para que se produjera dicha realidad lingüística en esos espacios, necesariamente tenía que haberse dado un contacto de ambos pueblos; porque las personas son los que generan esa realidad y no tanto la lengua en sí. Sin ello no sería factible la existencia de aquel fenómeno cultural, aún más en una lengua marginal como las de los indígenas amerindios. Marginales en el sentido de que el quechua y las lenguas amazónicas, durante ese periodo, no tenían poder político, cultural y social; debido a que el castellano ya se había impuesto como la lengua franca. Esto también a la vez revela que la interrelación entre esas dos culturas no es exclusiva de aquella época, sino que viene de muchos años atrás. Puesto que los exploradores no llevan el quechua como medio de dominio o de implantación en las comunidades amazónicas, simplemente son seres circunstanciales en el lugar. Tampoco es posible que en pocos días se formen personas bilingües, por arte de magia y en ambos lados.

\section{Conclusión}

Desde mediados del siglo XIX y hasta los inicios del siglo XX existían los pueblos amazónicos de la familia lingüística Arawak en las montañas de Huanta y Lamar del departamento de Ayacucho. Estuvieron muy cerca de los territorios de los pueblos quechuas que habitaban en las estribaciones altas de las cordilleras occidentales. Este elemento geográfico bordea los territorios de Huanta hasta la península de la provincia de Tayacaja, del departamento de Huancavelica.

El bilingüismo de pueblos amerindios se debe a un contacto lingüístico muchos años antes de la entrada de los exploradores y del viajero. Ambos pueblos tuvieron una interrelación prolongada por varios factores, uno de ellos sería el intercambio de productos. Como consecuencia de esto se dio la necesidad de conocer una lengua de la Amazonía y la lengua andina quechua. 


\section{Referencias bibliográficas}

Alonzo Sutta, A. (2000). Algunas evidencias lingüísticas del contacto quechua-lengua amazónica. En Lengua y Sociedad, (4), 71-79.

Alonzo Sutta, A. y Ramos Rios, L. (2014). Préstamos léxicos del quechua y del castellano en el asháninka. En Lengua y Sociedad, 14 (1), 83-94.

García Marcos, F. (2015). Sociolingüística. Madrid: Editorial Síntesis.

Pío Aza, J. (1923). Vocabulario español-machiguenga. Lima: La Opinión Nacional.

Portillo, P. (1901). Las montañas de Ayacucho y los ríos Apurimac, Mantaro, Ene, Perené, Tambo y Alto Ucayali. Lima: Imprenta del Estado.

Raimondi, A. (1874). El Perú. (Tomo I). Lima: Imprenta del Estado.

Samanez Ocampo, J. (1980). Exploración de los ríos peruanos Apurímac, Eni, Tambo, Ucayali y Urubamba. Lima: Sesator.

Santos, F. y Barclay, F. (2005). Introducción. Guía etnográfica de la Alta Amazonía. Vol V. Lima: IFEA, xv-xli.

Solís Fonseca, G. (2001). Lenguas generales y política lingüística en la Amazonía peruana durante la Colonia. En Escritura y Pensamiento, (8), 9-24.

Valcárcel, D. (1974). La rebelión de Juan Santos. En Huanta en la cultura peruana. Meneses, P., Meneses, T. y Rondinel, V. (eds.). Lima: Nueva Educación; pp. 73-74. 